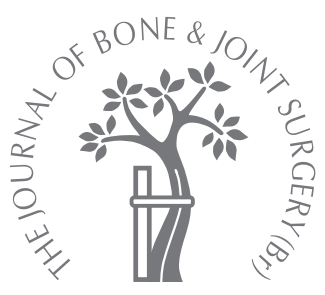

P. Hepp,

G. Osterhoff, M. Niederhagen,

B. Marquass,

T. Aigner,

A. Bader,

C. Josten,

R. Schulz

From University of

Leipzig, Leipzig,

Germany

In. Hepp, MD, Assistant

Professor, Orthopaedic

Surgeon

G. Osterhoff, MD, Research

Fellow

B. Marquass, MD

Orthopaedic Surgeon

C. Josten, MD, Professor and

Chairman

Department of Trauma and

Reconstructive Surgery

University of Leipzig,

Liebigstrasse 20, 04103 Leipzig

Germany.

M. Niederhagen, MD,

Pathologist

Department of Pathology

University of Munich (LMU),

Thalkirchner Strasse 36, 80337

Munich, Germany.

- T. Aigner, MD, MSc

Professor of Histopathology

Department of Pathology

University of Leipzig,

Liebigstrasse 26, 04103 Leipzig

Germany.

A. Bader, MD, Professor and

Chairman

R. Schulz, PhD, Head of

Cartilage Research Group

Department of Cell Techniques

and Applied Stem Cell Biology

University of Leipzig, Center of

Biotechnology and

Biomedicine, Leipzig, Germany.

Correspondence should be sent

to Dr P. Heppe; e-mail:

pierre.hepp@medizin.uni-

leipzig.de

(C)2009 British Editorial Society

of Bone and Joint Surgery

doi:10.1302/0301-620X.91B8.

$22057 \$ 2.00$

$J$ Bone Joint Surg $[\mathrm{Br}]$

2009;91-B:1110-19.

Received 13 November 2008 ;

Accepted after revision 24 April

2009

\title{
Perilesional changes of focal osteochondral defects in an ovine model and their relevance to human osteochondral injuries
}

\begin{abstract}
Perilesional changes of chronic focal osteochondral defects were assessed in the knees of 23 sheep. An osteochondral defect was created in the main load-bearing region of the medial condyle of the knees in a controlled, standardised manner. The perilesional cartilage was evaluated macroscopically and biopsies were taken at the time of production of the defect (T0), during a second operation one month later (T1), and after killing animals at three (T3; $n=8)$, four (T4; $n=8)$, and seven $(T 7 ; n=8)$ months. All the samples were histologically assessed by the International Cartilage Repair Society grading system and Mankin histological scores. Biopsies were taken from human patients $(n=10)$ with chronic articular cartilage lesions and compared with the ovine specimens. The ovine perilesional cartilage presented with macroscopic and histological signs of degeneration. At T1 the International Cartilage Repair Society 'Subchondral Bone' score decreased from a mean of 3.0 (SD 0 ) to a mean of 1.9 (SD 0.3) and the 'Matrix' score from a mean of 3.0 (SD 0 ) to a mean of 2.5 (SD 0.5). This progressed further at T3, with the International Cartilage Repair Society 'Surface' grading, the 'Matrix' grading, 'Cell Distribution' and 'Cell Viability' grading further decreasing and the Mankin score rising from a mean of 1.3 (SD 1.4) to a mean of 5.1 (SD 1.6). Human biopsies achieved Mankin grading of a mean of 4.2 (SD 1.6) and were comparable with the ovine histology at T1 and T3.
\end{abstract}

The perilesional cartilage in the animal model became chronic at one month and its histological appearance may be considered comparable with that seen in human osteochondral defects after trauma.

Owing to its avascularity, articular cartilage shows no significant capacity to recover after injury or destruction. ${ }^{1}$ Common clinical treatment such as microfracture drilling ${ }^{2}$ or osteochondral autologous transplantation (OATS) attempts to restore the damaged cartilage tissue. ${ }^{3,4}$ Microfracture drilling produces fibrocartilage of inferior quality with less mechanical load capacity and OATS has the disadvantage of the morbidity related to harvesting. ${ }^{5}$ Since the first description of autologous chondrocyte implantation (ACI) for deep cartilage defects in the human knee, ${ }^{6}$ the analysis of tissue engineering systems has grown in importance. ${ }^{7}$ Preclinical studies using large animal models with comparable stresses and strains reflecting the complex surgical site are indispensable. ${ }^{7,8}$ Previously, many studies dealing with cartilage regeneration used an acute cartilage defect in which generation and reconstruction of the defect were conducted at the same time. ${ }^{9-16}$ This practice does not represent the clinical situation. Most patients have a lengthy course following trauma to the cartilage, leading to chronic defects. This results in altered intra-articular homeostasis. ${ }^{17,18}$ Therefore, the encouraging and reproducible data obtained in experimental studies in vivo have been unattainable in the clinical setting. ${ }^{19-23}$ Although assessment of the biochemical and biomechanical alterations of the cartilage surrounding a defect has been performed in a semiqualitative manner, ${ }^{24}$ quantitative and reproducible data are not yet available.

This study assessed changes in the perilesional cartilage over time in focal osteochondral defects of the load-bearing area of the medial femoral condyle in an ovine knee using established histological scores. Biopsies of human cartilage adjacent to focal cartilage lesions were evaluated to assess whether the changes were comparable with the clinical appearance and to find when there was maximum morphological similarity between ovine and human perilesional cartilage.

\section{Materials and Methods}

A total of 23 female Merino-mix sheep, with a mean age of 22.3 months (SD 3) and a mean body weight of $65 \mathrm{~kg}$ (SD 63) were included in 


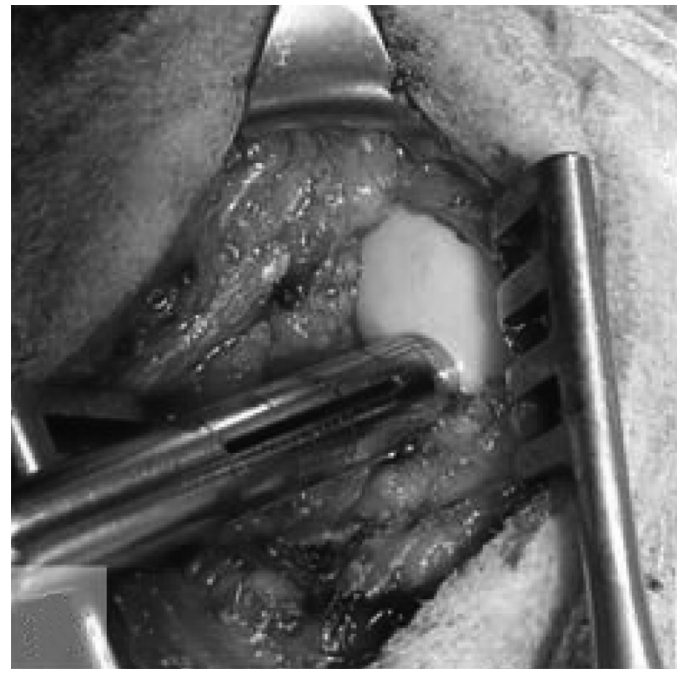

Fig. 1a

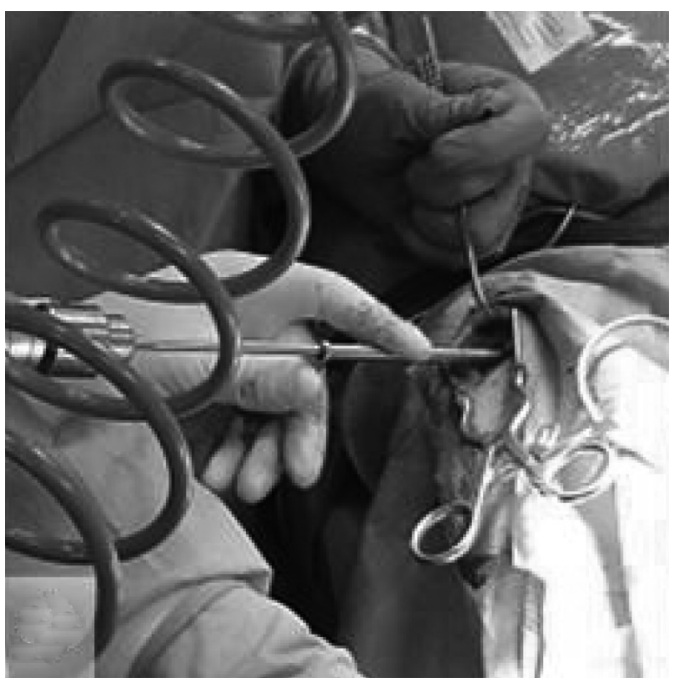

Fig. 1c

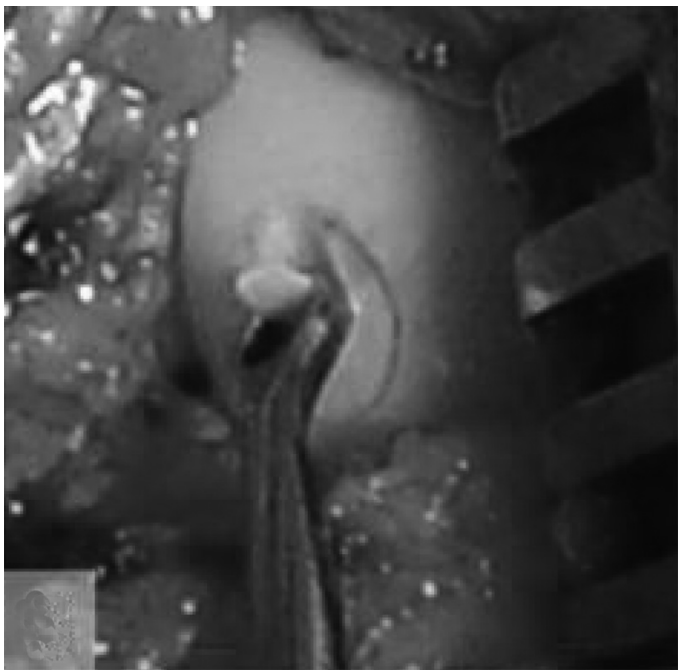

Fig. 1b

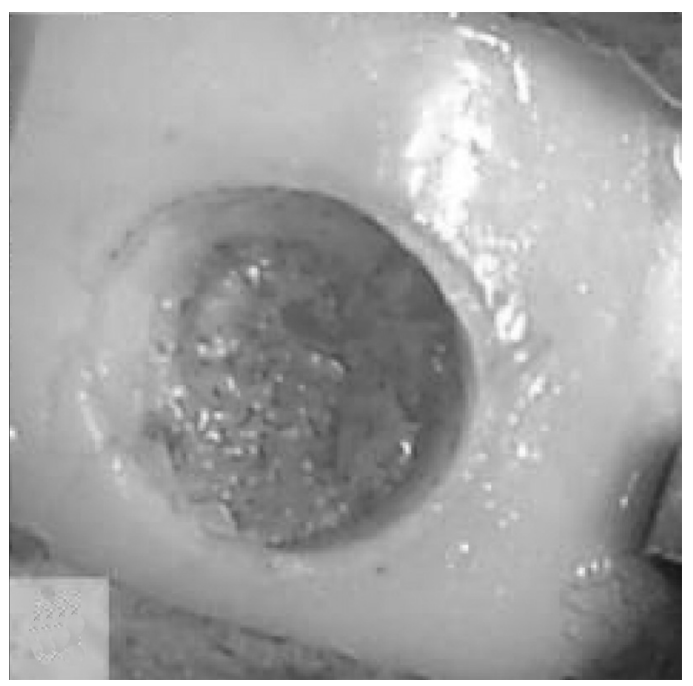

Fig. 1d

Photographs showing preparation of the defect. After marking the defect with a sharp tube (a), cartilage can be harvested by a curette (b). Under guidance of the tube, the subchondral endplate is penetrated by a drill (c), resulting in an osteochondral defect (d).

the investigation. The experiment was approved by the local legal representative (TVV33/04, State Directorate Leipzig, Germany) and performed in accordance with the guidelines of the European Convention for the Protection of Vertebrate Animals Used for Experimental and Other Scientific Purposes. ${ }^{25}$

Two operations were performed in each animal. After fasting for 12 hours, the animals were anaesthetised by intramuscular administration of $11.0 \mathrm{mg} / \mathrm{kg}$ ketamine, $0.22 \mathrm{mg} / \mathrm{kg}$ xylazine and $0.02 \mathrm{mg} / \mathrm{kg}$ atropine. ${ }^{26,27}$ After endotracheal intubation, anaesthesia was maintained by continuous intravenous administration of ketamine $(8.25 \mathrm{mg} / \mathrm{kg} / \mathrm{h})$ and xylazine $(0.165 \mathrm{mg} / \mathrm{kg} / \mathrm{h}) .{ }^{28}$ Analgesia was supplemented by fentanyl ( $0.1 \mathrm{mg}$ bolus intravenously) prior to surgery, ${ }^{29}$ and as needed during the operation. During anaesthesia, supplementary oxygen (flow: $81 / \mathrm{min}$ to $10 \mathrm{l} / \mathrm{min}$ ) was given, and in the event of capillary saturation falling below $90 \%$, ventilation was assisted manually. The knee joint was prepared in a standard sterile manner, the medial condyle was exposed by a small parapatellar medial arthrotomy, and the articular surface was assessed before and after creating the defect.

A standardised circular osteochondral defect $7 \mathrm{~mm}$ in diameter was created in the main load-bearing region of the medial condyle, extending for $2 \mathrm{~mm}$ into the subchondral bone (Fig. 1). First, a circular cartilage lesion $7 \mathrm{~mm}$ in diameter was made with a tube harvester (Arthrex Inc., Naples, Florida) without penetrating the subchondral bone. The 

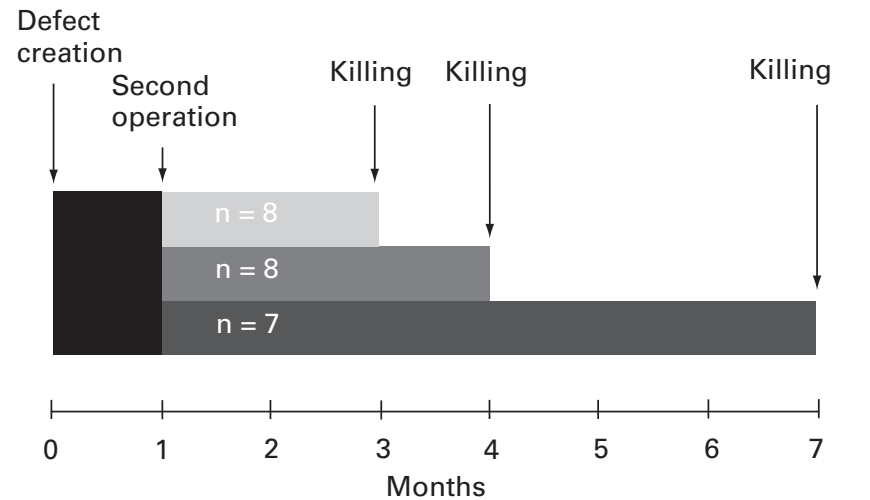

Fig. 2

The scheme for assessment of the sheep with osteochondral defects.

cartilage was carefully excised manually down to the calcified cartilage layer with a curette. Before drilling, and in order to minimise damage to the perilesional cartilage, a sharp tube was pressed on to the osteochondral border ${ }^{30}$ as a guide for the $7 \mathrm{~mm}$ cylindrical flat-tipped drill (B. Braun Melsungen AG, Melsungen, Germany). The depth of the osteochondral defect was controlled by a custom-made drill stop on the tube. There was bleeding at the base of the defect in all cases.

A $1.8 \mathrm{~mm}$ diameter osteochondral biopsy specimen was harvested $2 \mathrm{~mm}$ from the edge of the cartilage lesion of the left knee in eight sheep using a 13-gauge Jamshidi bone marrow biopsy needle (Cardinal Health Inc., McGaw Park, Illinois).

One month after the first operation, a second procedure was performed (T1). The knee was opened in the manner previously described and a $1.8 \mathrm{~mm}$ diameter biopsy specimen was obtained as before.

All the wounds were sutured and covered with a spray bandage. The animals received metamizol (Novaminsulfon, Ratiopharm, Ulm, Germany) as analgesia for the first seven days. Immediately after operation, they were allowed to move freely and bear weight fully without restriction. They were monitored at all times by a veterinary surgeon. At three months after the first operation eight animals were killed (T3), a further eight after four months (T4) and seven after seven months (T7) (Fig. 2).

At the time of the two operations and after killing, the appearance of both the osteochondral lesion and the marginal area of the defect was rated according to the International Cartilage Repair Society Cartilage Injury Classificaton (ICRS-CIC), ${ }^{31}$ and possible abnormalities within the joint were documented.

The biopsy specimens of the perilesional cartilage of the sheep were prepared as described below for the human tissue samples. After removing the left femur, osteochondral cylinders $(15 \times 15 \times 15 \mathrm{~mm})$ containing the defect and the surrounding cartilage were obtained using a water-cooled precision-saw (Exakt-Trennschleifsystem, Exakt Apparatebau GmbH,
Norderstedt, Germany), the tissue samples fixed in 4\% buffered formalin for one to three days. The specimens were then decalcified in a $20 \%$ EDTA solution at $\mathrm{pH} 7.4$ for 16 weeks. They were then dehydrated in a graded series of ethanol, embedded in paraffin, and sectioned at a thickness of $3 \mu \mathrm{m}$. After dewaxing the slices, a described staining protocol for Safranin O, haematoxylin and eosin $(\mathrm{HE})^{32}$ was followed to enable histological examination. In some cases an additional toluidine blue staining was performed to provide better contrast. These two or three stains were necessary to enable precise histomorphological analysis of the biopsies. ${ }^{33,34}$ Histological scoring of the perilesional cartilage was undertaken using the Mankin score ${ }^{35}$ and the ICRS Visual Histological Assessment Scale (ICRS-VHS). ${ }^{33}$

Human biopsies. A total of ten patients were recruited after appropriate Institutional Board Review approval and giving their informed consent. Inclusion criteria were age between 16 and 65 years, and radiological (MRI) evidence of a focal grade IV osteochondral lesion, according to the ICRS classification, requiring arthroscopy. ${ }^{31}$ The presence of any cartilage lesion, including the size and the grade, was recorded.

The patients underwent diagnostic arthroscopy and routine exploration of the joint cavity. Abnormal findings were recorded and graded using ICRS-CIC. ${ }^{31}$ The surgeon then obtained a $1.8 \mathrm{~mm}$ diameter biopsy specimen as described for the animal model above. ${ }^{36}$ Any relevant surgical therapeutic procedures necessary were then performed and microfracture ${ }^{2}$ was undertaken.

The biopsy specimens were fixed in $4 \%$ buffered formaldehyde for a maximum duration of six to nine hours. After fixation, decalcification using $20 \%$ EDTA pH 7.4 was undertaken for at least 12 to 15 hours. Afterwards the specimens were dehydrated, embedded in paraffin, and sectioned at a thickness of $2 \mu \mathrm{m}$ with a conventional microtome. The sections were stained with Safranin-O, HE and toluidine blue, and graded using the histological scoring system described by Mankin et al, ${ }^{35}$ with reliability testing according to van der Sluijs et al. ${ }^{37}$

Statistical analysis. Data were expressed as mean with SD, their normal distribution being examined by the Kolmogorov-Smirnov test and for homogeneity using Levene's test. For the animal model a Kruskal-Wallis test was used for each parameter against time. If significant findings were detected, the Mann-Whitney U test was applied for data which were not normally distributed to selectively analyse differences that were considered statistically significant if the p-value was $<0.05$. Correlations were calculated using Spearman's rank correlation coefficient, and the correlation was considered significant for values of $r>0.05$ and $\mathrm{p}<0.001$. Statistical analysis was performed with SPSS 14.0 software (SPSS Inc., Chicago, Illinois).

\section{Results}

Animals. All animals tolerated anaesthesia and their surgical procedures well. Although some sheep limped for the initial two to three days after operation, normal gait soon 


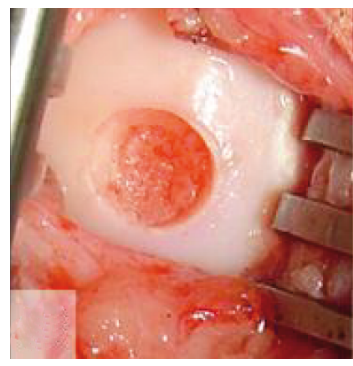

Fig. 3a

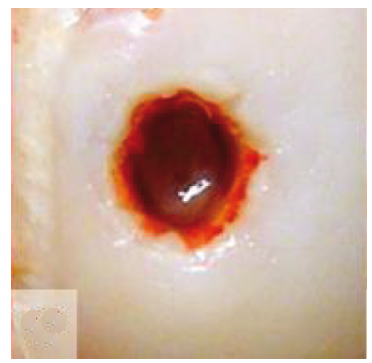

Fig. 3c

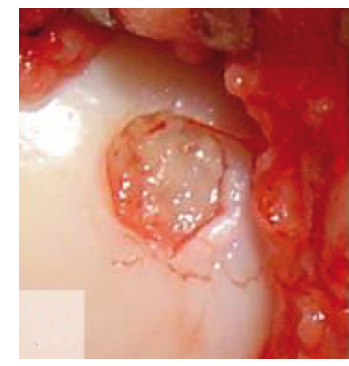

Fig. 3b

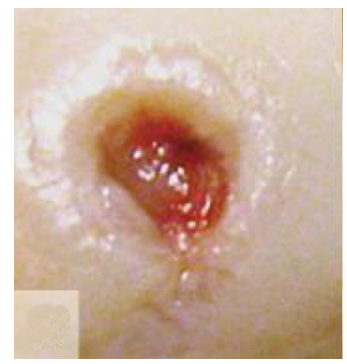

Fig. 3d

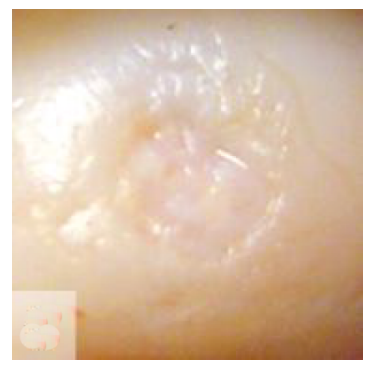

Fig. 3e

The image sequence shows the macroscopic appearance of the defect and the perilesional cartilage (a) immediately after creation of the defect (T0), (b) after one (T1), (c) three (T3), (d) four (T4) and (e) seven (T7) months.

returned and no swelling of the joints was observed in any animal prior to the creation of the defect, interval biopsies and euthanasia.

According to the ICRS-CIC, the cartilage defects were grade IV lesions when they were produced (T0). Although all (23 of 23) defects still extended into the subchondral bone after one month (T1) (mean 4, SD), a filling of the defect after three months (T3) with a mean grade of 3.5 (SD 0.5 , at four months (T4) with a mean grade of 2.6 (SD 0.5 ) and at seven months (T7) with a mean grade of 2.6 (SD 0.5). There was a statistically significant change in the mean grade from T1 to T3 $(\mathrm{p}=0.037)$ as well as from T4 to T7 ( $p=0.009$, Mann-Whitney U test). In all groups, the defects were distinguishable from the surrounding tissue (Fig. 3). A lucid softening of the tibial cartilage was seen opposite the femoral defects in all animals.
Macroscopically, the perilesional cartilage showed timedependent changes. No damage was seen after the initial defect (T0). At four weeks (T1) the border showed mainly fibrillation with slight softening and additional superficial lacerations and fissures, corresponding to ICRS-CIC grades Ia and Ib. After three, four and seven months (T3, T4 and T7) damage to the cartilage appeared to extend deeper, albeit still involving $<50 \%$ of the thickness. Macroscopic changes correlated strongly both with time (perilesional cartilage: $r=0.95$; defect: $r=-0.63$; both $\mathrm{p}<0.001)$ and noticeably with each other $(\mathrm{r}=-0.50 ; \mathrm{p}<0.001)$ (Fig. 4).

In the histological analysis, the margins of the undamaged cartilage contained chondrocyte clusters and had lost metachromasia and Safranin-O staining. Further away from the lesion, the chondrocytes remained organised in columns, but the columns were tilted towards the lesion. The cellularity of the immediate neighbourhood of the lesion was reduced in two of the 23 cases (Figs 5 and 6).

The specimens gathered at T0 featured a mean Mankin score of 0.50 (SD 0.8). At one month, a tendency towards higher values could be detected in the structure, cellular abnormalities and matrix staining, with superficial fissures in nine knees and clusters of chondrocytes in two, but these were not statistically significant $\left(\mathrm{P}_{\text {structure }}=0.11 ; \mathrm{P}_{\text {cell }}=0.26\right.$; $\mathrm{P}_{\text {matrix }}=0.81$, Mann-Whitney $\mathrm{U}$ test). Comparing the results of T3 with T1, a structural degradation was seen $\left(\mathrm{P}_{\text {struc }}<0.01\right)$ which was accompanied by cell destruction $\left(\mathrm{P}_{\text {cell }}<0.01\right)$ and a reduced matrix staining reaching into the interterritorial layers $\left(\mathrm{P}_{\text {matrix }}<0.01\right.$, Mann-Whitney $\mathrm{U}$ test $)$. Specimens at T4 and T7 showed no significant differences from the T3 analogue regarding the macroscopic findings (Table I).

The ICRS-VHS resulted in similar trends in evaluation according to the Mankin grading. There were significant signs of degeneration ( $p=0.03$, Mann-Whitney $U$ test $)$ for the ICRS parameter matrix after one month. The distinct degenerative progress from T1 to T3 with superficial discontinuities $\left(\mathrm{P}_{\text {surface }}<0.01\right)$, alterations of the extracellular matrix $\left(\mathrm{P}_{\text {matrix }}=0.023\right)$, clustering of chondrocytes $\left(\mathrm{P}_{\text {cell distribution }}<0.01\right)$ and cell deterioration $\left(\mathrm{P}_{\text {cell viability }}\right.$ $<0.01$, Mann-Whitney U test) showed high levels of significance. Pathological calcifications of cartilage tended to occur three months after creation of the defect $(\mathrm{T} 0+\mathrm{T} 1$ : $\mathrm{n}=0, T 3: \mathrm{n}=1, T 4: \mathrm{n}=3, \mathrm{~T} 7: \mathrm{n}=2)$ but were not significant when the groups were compared statistically $(\mathrm{p}=0.22$, Kruskal-Wallis test).

The subchondral bone, which appeared intact in the beginning, showed clear signs of alteration $(\mathrm{p}<0.01$, MannWhitney $\mathrm{U}$ test), with increased bone remodelling in all cases and sporadic bone necrosis in two after only one month. Two months later (T3), bone necrosis was present in all specimens ( 8 of 8 ) with additional fracture callus at the base in one animal ( $\mathrm{p}<0.01$, Mann-Whitney $U$ test). The outcome of this is an accumulated histological ICRS score with a significant downward progress from T0 to T1 $(\mathrm{p}<0.01)$ and from T1 to T3 ( $\mathrm{p}<0.01$, Mann-Whitney $\mathrm{U}$ test). The 

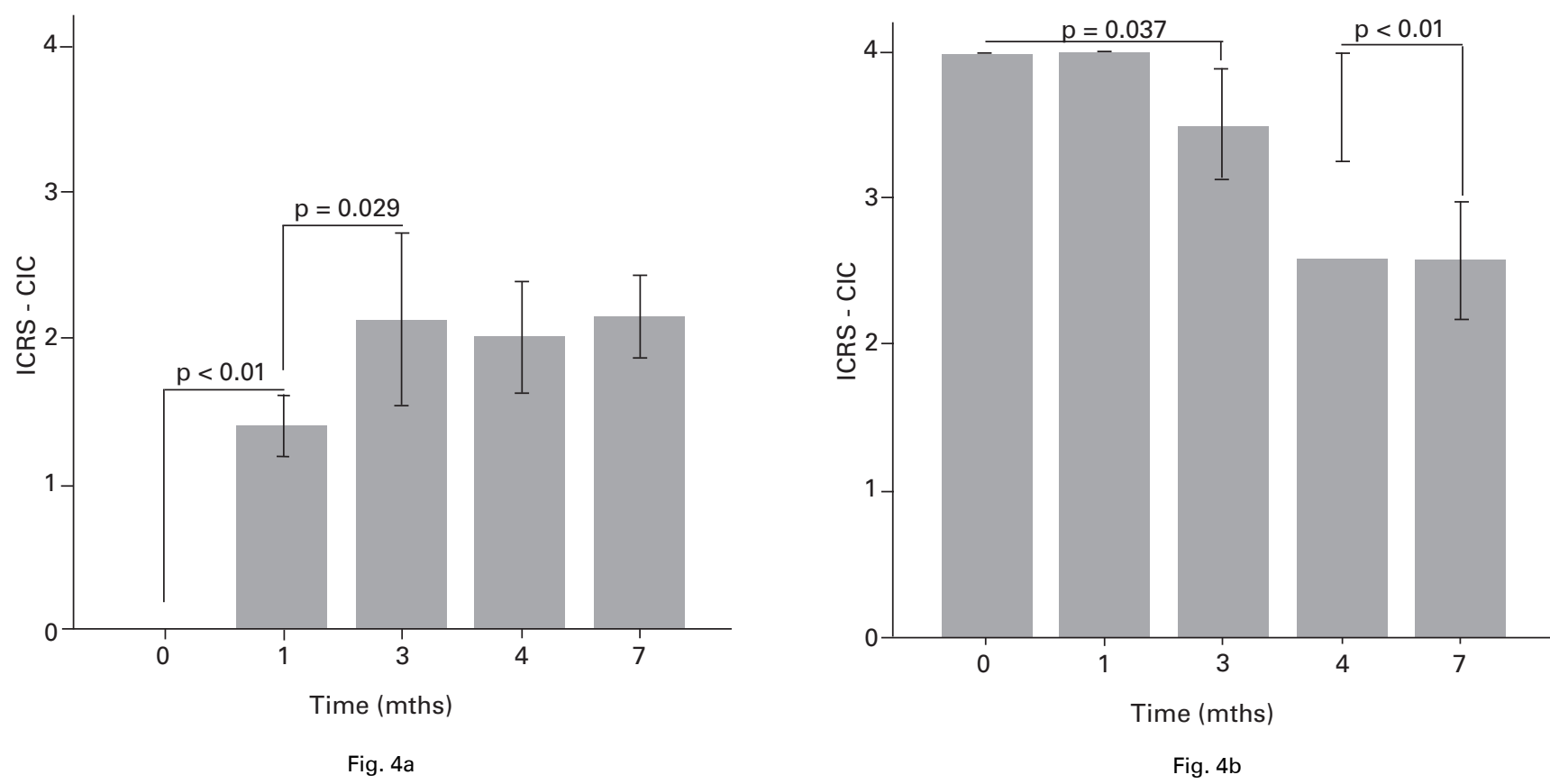

Histograms showing the results of the macroscopic evaluation of the perilesional cartilage (a) and the defect (b) using the International Cartilage Repair Society Cartilage Injury Classification (ICRS-CIC) (error bars represent two standard errors).

collected values at T4 and T7 showed no statistical differences from each other and from T3 (Table II).

The Mankin histological score and ICRS-VHS clearly correlated with time $\left(\mathrm{r}_{\text {Mankin }}=0.73, \mathrm{p}<0.01 ; \mathrm{r}_{\text {ICRS-VHS }}=\right.$ $-0.86, \mathrm{p}<0.01)$ as well as with each other $(\mathrm{r}=-0.82$, $\mathrm{p}<0.01)$. Both scores correlated with the macroscopic findings of the perilesional cartilage (Mankin: $r=0.60$, $\mathrm{p}<0.01$; ICRS: $\mathrm{r}=-0.67, \mathrm{p}<0.01$ ) and especially of the subchondral bone $(\mathrm{r}=-0.64, \mathrm{p}<0.01)$.

Human biopsies. Arthroscopic perilesional biopsies were evaluated from ten patients at a mean of 7.6 months $(0.5$ to 24) after injury to the knee (Table III, Figs 5 F, 6 E and F). None of the knees showed macroscopic signs of generalised osteoarthritis. No softening of cartilage was found further away from the defects. After biopsy, harvesting and subsequent debridement, the borders of the lesions were found to have stable tissue. Three patients required meniscal surgery and one had reconstruction of the anterior cruciate ligament. According to the Mankin score, all specimens except one showed superficial fissures in the radial layer. In one case superficial cartilage was absent, but in none of the biopsies was the calcified layer involved (Table I). All biopsies showed changes on the cellular level, eight with occurrence of chondrocyte clusters that were accompanied by initial hypocellularity in one case. In all but one specimen, mild to moderate reduction in the intensity of Safranin-O staining could be seen, especially in the superficial third. No correlation was found between size or time and the histological or macroscopic scores.

\section{Discussion}

We are aware of no data in the current literature concerning the evaluation of perilesional cartilage using established classification systems. Our results correspond with those of other studies in large animals, where staining and proteoglycan loss, hypercellularity and cartilage necrosis were observed in the edges of the defect. ${ }^{38-42}$ However, because all the listed literature refers to the edges, it is difficult to determine to what extent these data apply to the perilesional cartilage investigated in the present study.

Although the site of the defect showed increased filling, the macroscopic appearance of the perilesional cartilage in the animal model was dominated by spreading degenerative changes. Similar findings were described for osteochondral defects with a diameter of $6 \mathrm{~mm}$ in goats. ${ }^{39,43}$ Histological evaluation of the perilesional cartilage indicated clear signs of degeneration incorporating the subchondral bone after only one month. These changes were progressive at three months. However, the Mankin histological scores showed values corresponding only to rather moderate cartilage damage. This is in accordance with histological results described for comparable macroscopic findings in the articular cartilage of sheep. ${ }^{44}$ At four and seven months, no further significant progression of the degeneration could be seen at the microscopic level, but there was a tendency towards regression of matrix degeneration and a consistent excess of subchondral bone mineralisation. A possible explanation for this might be mechanical stabilisation of the edges of the defect due to its increasing filling. 


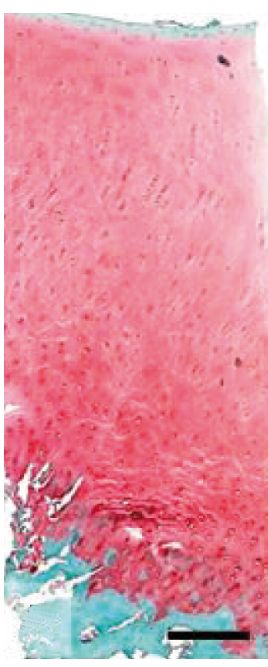

Fig.5a

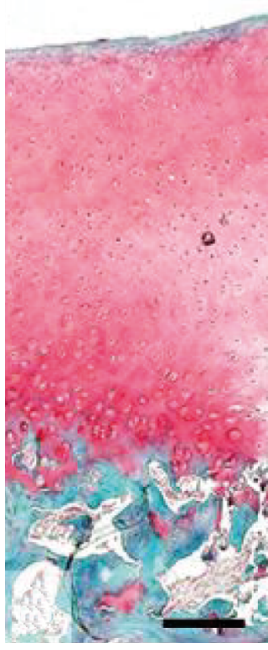

Fig. $5 b$

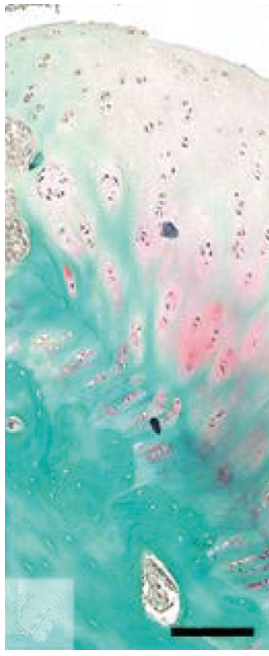

Fig. 5c

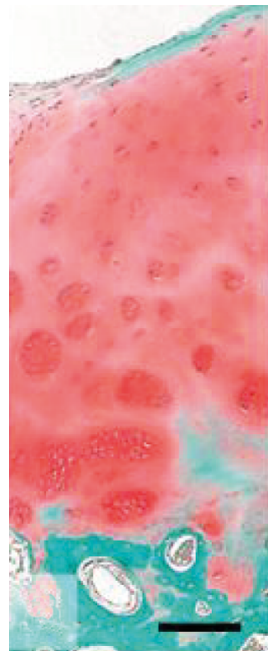

Fig. 5d

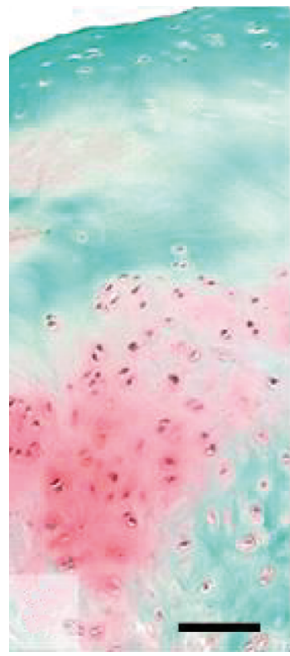

Fig. $5 e$

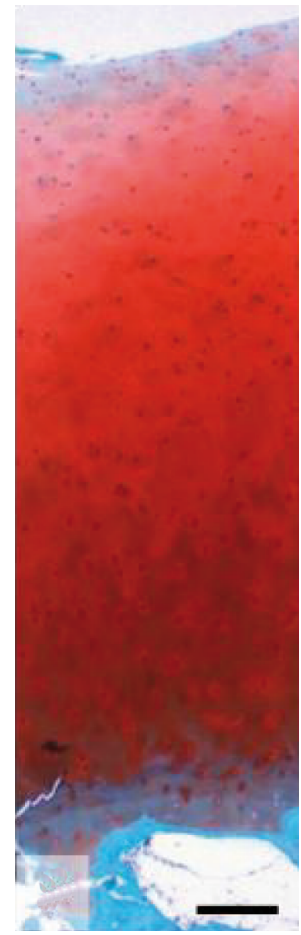

Fig. $5 f$

Histological appearance of the perilesional cartilage (Safranin-O; $\times 4$; bar $=500 \mu \mathrm{m}$ ). In the animal model at the time of creation of the defect (a) there is normal hyaline cartilage with its characteristic columnar structure. At one month (b), initial hypercellular disorganisation, a slight interterritorial stain loss and subchondral bone remodelling can be seen. At three months (c), bone remodelling increases and chondrocyte clusters appear. Four months after creation of the defect (d) noticeable hypocellularity is visible accompanied by many cell clusters. These patterns persist unchanged at seven months (e). The human biopsy (f) is of greater thickness and shows hypercellularity, a loss of the columnar structure and a few chondrocyte clusters, very similar to the ovine biopsies at one and three months.

We do not know to what extent altered biomechanical stress patterns and the disturbed cytokine and transmitter balance contribute to the observed changes in the perilesional cartilage, and whether or not these are simply responses to the original defect. At a distance of $2 \mathrm{~mm}$ from the edge of the defect, all three factors can be of influence. ${ }^{45}$ The macroscopic findings with fissures originating from the defect at T1 suggest direct expansion of the lesion. The early remodelling of subchondral bone can be explained either by the inflicted injury itself or by biomechanical overload. ${ }^{44,46,47}$ Finally, the quick cellular reaction and loss of proteoglycans indicate a disturbance of joint homeostasis. ${ }^{47-49}$ The observed macroscopic tibial changes opposite to the defects have been described previously. ${ }^{41,42,49,50}$ Mastbergen et $\mathrm{al}^{50}$ concluded that these may be a reaction to increased proteinase and aggrecanase activity in the joint, rather than due to surgical damage. Previous studies attribute insufficient healing following intervention in older cartilage lesions to an imbalance of the intra-articular metabolic environment. ${ }^{15-17}$ Consequently, the results of this investigation suggest that this imbalance also leads to degeneration of the perilesional cartilage.

Remodelling of subchondral bone below the perilesional cartilage might be a reaction to elevated biomechanical loads, resulting in increased stiffness of the subchondral bone and hence higher stresses on the cartilage matrix. ${ }^{44-46}$ This is another possible reason for the observed initial loss of proteoglycans in the perilesional cartilage. ${ }^{50,51}$ Irrespective of which process was the initial one, the parallel occurrence of cartilage degeneration and remodelling of subchondral bone after one month indicates that the defect became chronic. ${ }^{48}$ Evidence for this is even more obvious after three months, when the imbalance of joint homeostasis may become manifest in the histological picture.

All elevated human biopsies presented with degenerative changes of the cartilage, particularly in the superficial third. At the cellular level, each of the samples showed at least a diffuse hypercellularity. These histological results are consistent with data published for similar macroscopic patterns in human knees. ${ }^{51-53}$ In view of the documented size of the defects and the mean time between trauma and intervention of 7.6 months, it is apparent that most of the defects examined were of a chronic nature. Although there were no macroscopic signs of concurrent generalised osteoarthritis in the human knees, this could not be completely excluded at the histological level and must be considered in the comparison between ovine and human biopsies. The mean age of our patients of about 45 years is similar to that of patients who have been considered for cartilage repair. ${ }^{53-55}$ 


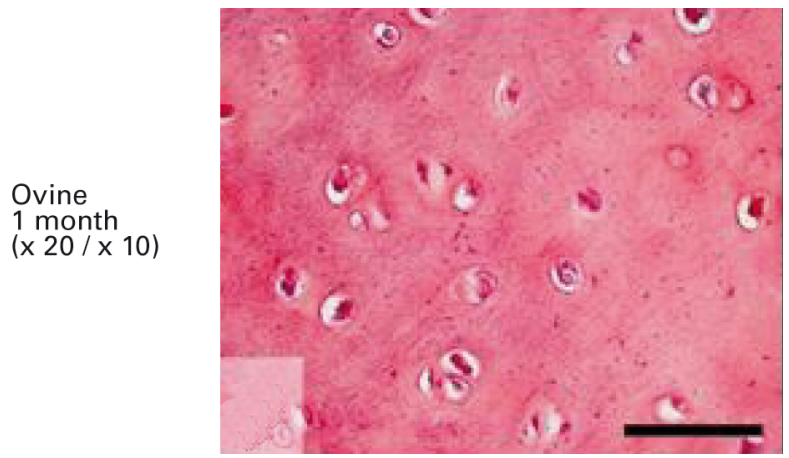

Fig. 6a

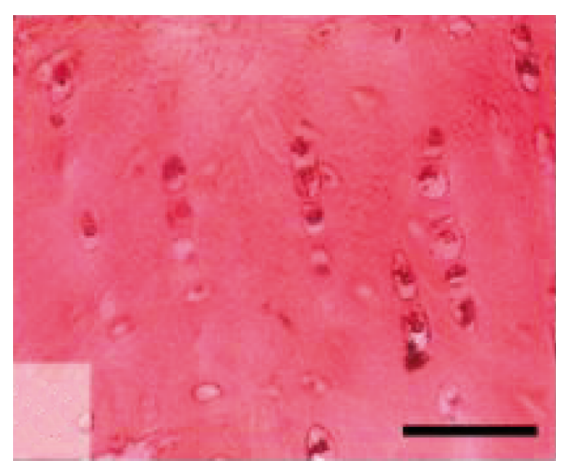

Fig. 6c

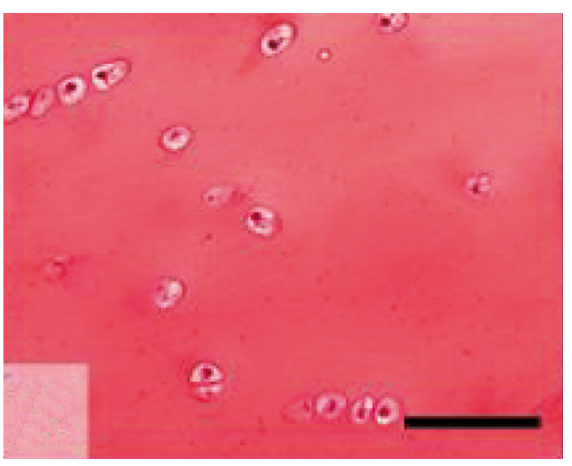

Fig. $6 e$

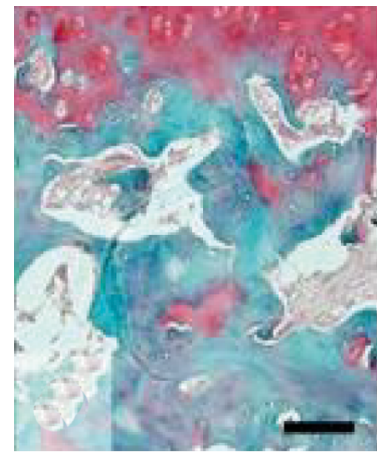

Fig. $6 \mathrm{~b}$

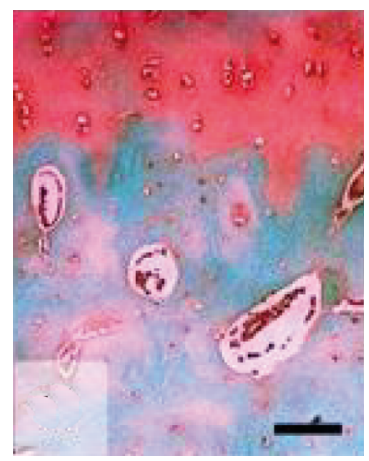

Fig. $6 d$

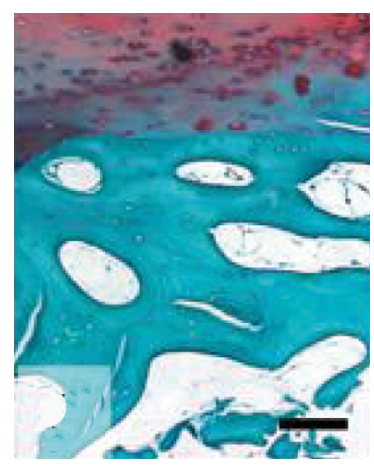

Fig. $6 f$

Histological appearance of the perilesional cartilage (Safranin-O ?20/? 10; bar $=100 ? \mathrm{~m})$. The transitional zone shows hypercellularity in both the ovine $(\mathrm{a}+\mathrm{c})$ and the human (e) biopsies. Increasingly, subchondral bone remodelling and excessive mineralisation occur in the animal model (from b to d). Both could also be seen in the human biopsies (f).

Because of the different anatomical dimensions, the absolute sizes of the defects in human and ovine knees cannot be compared. Thus, in each joint a critical size for a lesion must be determined. A defect diameter of $10 \mathrm{~mm}$ $\left(0.78 \mathrm{~cm}^{2}\right)$ has been shown to be critical for increased perilesional contact stresses in the human knee. ${ }^{37}$ Except in one patient, all of the human biopsies were obtained from knees with osteochondral lesions larger than this threshold size.
In the ovine knee, which has only about $60 \%$ of the contact area of a human knee, a defect of $7 \mathrm{~mm}$ in diameter might be reasonably assumed to be critical. In large animal models, osteochondral defects with a diameter of $7 \mathrm{~mm}$ were not able to heal completely on their own. ${ }^{15,16,29,38,39}$ This is analogous to our macroscopic findings for the defect zone.

The applied animal model is not suitable for every possible pattern of clinical defect. Purely chondral defects which do 
Table I. Histological evaluation of the perilesional cartilage by the Mankin histological score ${ }^{35}$ (all values mean, SD)

\begin{tabular}{lllllll}
\hline & \multicolumn{1}{l}{ Sheep } & & & \\
\cline { 2 - 7 } & T0 $(\mathbf{n}=\mathbf{8})$ & $\mathbf{T 1}(\mathbf{n}=\mathbf{2 3})$ & $\mathbf{T 3}(\mathbf{n}=\mathbf{8})$ & T4 (n= 8) & T7 (n= 7) Human \\
\hline Mankin (SD) & $0.5(0.8)$ & $1.3(1.4)$ & $5.1\left(1.6^{*}\right) \mathrm{p}<0.001$ & $5.1(1.9)$ & $4.4(2.6)$ & $4.2(2.0)$ \\
Structure (SD) & $0.0(0.0)$ & $0.4(0.5)$ & $2.4\left(0.7^{*}\right) \mathrm{p}<0.001$ & $2.4(0.7)$ & $2.3(1.8)$ & $1.2(1.0)$ \\
Cellular abnormalities (SD) & $0.1(0.4)$ & $0.5(0.7)$ & $1.5\left(0.8^{*}\right) \mathrm{p}=0.003$ & $1.5(0.8)$ & $1.4(0.5)$ & $1.9(0.7)$ \\
Matrix staining (SD) & $0.4(0.5)$ & $0.4(0.5)$ & $1.3\left(0.5^{*}\right) \mathrm{p}=0.004$ & $1.3(0.5)$ & $0.7(0.5)$ & $1.1(0.7)$ \\
\hline * indicates a significant difference to T1, $\mathrm{p}<0.05$ (animal model only) & & &
\end{tabular}

Table II. Animal model. Histological evaluation of the perilesional cartilage by the International Cartilage Repair Society Visual Histological Assessment Scale (ICRS-VHS) ${ }^{31}$ (all values mean, SD)

\begin{tabular}{|c|c|c|c|c|c|}
\hline & \multicolumn{5}{|l|}{ Sheep } \\
\hline & TO $(n=8)$ & $T 1(n=23)$ & $T 3(n=8)$ & $\mathrm{T} 4(\mathrm{n}=8)$ & $\mathrm{T7}(\mathrm{n}=7)$ \\
\hline ICRS-VHS (SD) & $17.9(0.4)$ & $15.7\left(1.6^{*}\right) p<0.001$ & $9.1\left(3.4^{\dagger}\right) p<0.001$ & $8.5(3.1)$ & $9.7(4.2)$ \\
\hline Surface (SD) & $3.0(0.0)$ & $2.5(1.2)$ & $0.4\left(1.1^{\dagger}\right) p=0.02$ & $0.0(0.0)$ & $0.4(1.1)$ \\
\hline Matrix (SD) & $3.0(0.0)$ & $2.5\left(0.5^{*}\right) p=0.03$ & $1.9\left(0.4^{\dagger}\right) p=0.023$ & $2.0(0.0)$ & $1.7(0.5)$ \\
\hline Cell distribution (SD) & $2.9(0.4)$ & $2.8(0.4)$ & $1.6\left(0.7^{\dagger}\right) p<0.001$ & $1.5(0.8)$ & $1.7(0.5)$ \\
\hline Cell population viability (SD) & $3.0(0.0)$ & $3.0(0.0)$ & $1.8\left(1.0^{\dagger}\right) p=0.007$ & $2.3(1.0)$ & $2.4(1.0)$ \\
\hline Subchondral bone (SD) & $3.0(0.0)$ & $1.9\left(0.3^{*}\right) p<0.001$ & $0.9\left(0.4^{\dagger}\right) p<0.001$ & $0.9(0.6)$ & $1.3(0.5)$ \\
\hline Cartilage mineralisation (SD) & $3.0(0.0)$ & $3.0(0.0)$ & $2.6(1.1)$ & $1.9(1.6)$ & $2.1(1.5)$ \\
\hline
\end{tabular}

* indicates a significant difference to T0

$\dagger$ indicates a significant difference to $T 1, p<0.05$ (animal model only)

Table III. Data from human cartilage biopsies from the medial femoral condyle $(n=10)$

\begin{tabular}{|c|c|c|c|c|c|c|}
\hline Patient & Gender $^{*}$ & $\begin{array}{l}\text { Age } \\
\text { (yrs) }\end{array}$ & $\begin{array}{l}\text { Time trauma to surgery } \\
\text { (mths) }\end{array}$ & $\begin{array}{l}\text { Defect size } \\
\left(\mathrm{cm}^{2}\right)\end{array}$ & ICRS-CIC $^{\dagger}$ & Concurrent injuries $^{\ddagger}$ \\
\hline 1 & $\mathrm{M}$ & 22 & 0.5 & 5 & 4 & None \\
\hline 2 & $\mathrm{M}$ & 48 & 2 & 5.25 & 4 & MM \\
\hline 3 & $\mathrm{~F}$ & 51 & 2 & 3 & 4 & None \\
\hline 4 & $\mathrm{M}$ & 49 & 3 & 4.5 & 4 & None \\
\hline 5 & $M$ & 44 & 5 & 1 & 4 & None \\
\hline 6 & $\mathrm{~F}$ & 49 & 5 & 1.5 & 4 & $\mathrm{MM}$ \\
\hline 7 & $M$ & 45 & 9 & 4.5 & 4 & None \\
\hline 8 & $M$ & 60 & 10 & 4 & 4 & MM, LM \\
\hline 9 & M & 61 & 15 & 0.25 & 4 & None \\
\hline 10 & M & 17 & 24 & 2.25 & 4 & $\mathrm{ACL}, \mathrm{MM}$ \\
\hline Mean (range) & & 44.6 (17 to 61$)$ & 7.6 (0.5 to 24$)$ & 3.1 (0.5 to 53$)$ & 4.0 (4.0 to 4.0$)$ & \\
\hline
\end{tabular}

* M, male; F, female

† ICRS-CIC, International cartilage repair society-cartilage injury classification

‡ MM, medial meniscus lesion; LM, lateral meniscus lesion; $A C L$, rupture of the anterior cruciate ligament

not affect the subchondral bone are difficult to standardise. ${ }^{7,33,43}$ With a depth of $2 \mathrm{~mm}$, the described model resembles a severe osteochondral injury. In clinical practice, osteochondral lesions may not be the most frequent pattern of injury, but they account for over $9 \%$ of all cartilage lesions ${ }^{40}$ and therefore pose a substantial problem.

In this study we investigated the perilesional cartilage at a distance limited to $2 \mathrm{~mm}$ from the defect, because for ethical reasons it was not acceptable to harvest biopsies further away in human knees. Another limitation was the short follow-up of seven months. For future studies it would be useful to address multiple sites in the joint and include longer follow-up to see how quickly and how far degenerative changes spread with time.

The perilesional cartilage in the ovine defect model showed signs of chronic degeneration at one and three months. These may be comparable with those seen in cross-sectional human biopsies of chronic defects after trauma. Data are provided for future research in tissueengineered cartilage substitutes and their regenerative potential in a chronic setting. Further research may focus on the question of whether the degeneration of the perilesional cartilage can be arrested or slowed by various techniques of repair. As a period of four weeks corresponds to 
the usual duration for cell culture of ACI as well as bone marrow-based approaches ${ }^{56}$ future pre-clinical investigations on both cartilage and osteochondral repair may be performed on comparable chronic animal models.

The authors would like to thank Dr P. Madaj-Sterba and G. Lemm (Leipzig, Germany) for their outstanding dedication to this project, particularly for animal care. This work was supported by the formel.1 programme of the Medical Faculty of Leipzig (Number 55/2005, number 97/2007), by the German Ministry of Education and Research (BMBF Grant 0313836), and by the German Research Foundation (Project BA 1025/2-1).

No benefits in any form have been received or will be received from a commercial party related directly or indirectly to the subject of this article.

\section{References}

1. Tuan RS. Skeletal tissue engineering in cartilage replacement: future perspectives and the new age of regenerative medicine. In: Hendrich C, Nöth U, Eulert J, eds. Cartilage surgery and future perspectives. Berlin: Springer, 2003:185-97.

2. Steadman JR, Rodkey WG, Singleton SB, Briggs KK. Microfracture technique for full thickness chondral defects: technique and clinical results. Operat Tech Orthop 1997;7:300-4

3. Kim HK, Moran ME, Salter RB. The potential for regeneration of articular cartilage in defects created by chondral shaving and subchondral abrasion: an experimental investigation in rabbits. J Bone Joint Surg [Am] 1991;73-A:1301-15.

4. Hangody L, Kish G, Kárpati Z, et al. Mosaicplasty for the treatment of articular cartilage defects: application in clinical practice. Orthopedics 1998;21:751-6.

5. Hunziker EB. Articular cartilage repair: basic science and clinical progress: a review of the current status and prospects. Osteoarthritis Cartilage 2002;10:432-63.

6. Brittberg M, Lindahl A, Nilsson A, et al. Treatment of deep cartilage defects in the knee with autologous chondrocyte transplantation. N Eng/ J Med 1994;331:889-95.

7. Reinholz GG, Lu L, Saris DB, Yaszemski MJ, O'Driscoll SW. Animal models for cartilage reconstruction. Biomaterials 2004;25:1511-21.

8. Buma P, Schreurs W, Verdonschot N. Skeletal tissue engineering: from in vitro studies to large animal models. Biomaterials 2004;25:1487-95.

9. Munirah S, Samsudin OC, Chen HC, et al. Articular cartilage restoration in loadbearing osteochondral defects by implantation of autologous chondrocyte-fibrin constructs: an experimental study in sheep. J Bone Joint Surg [Br] 2007;89-B:1099-109.

10. Barnewitz D, Endres M, Kruger I, et al. Treatment of articular cartilage defects in horses with polymer-based cartilage tissue engineering grafts. Biomaterials 2006;27:2882-9.

11. Chiang H, Kuo TF, Tsai CC, et al. Repair of porcine articular cartilage defect with autologous chondrocyte transplantation. J Orthop Res 2005;23:584-93.

12. Guo X, Wang C, Zhang Y, et al. Repair of large articular cartilage defects with implants of autologous mesenchymal stem cells seeded into beta-tricalcium phosphate in a sheep model. Tissue Eng 2004;10:1818-29.

13. Jiang CC, Chiang H, Liao CJ, et al. Repair of porcine articular cartilage defect with a biphasic osteochondral composite. J Orthop Res 2007;25:1277-90.

14. Liu Y, Chen F, Liu W, et al. Repairing large porcine full-thickness defects of articular cartilage using autologous chondrocyte-engineered cartilage. Tissue Eng 2002;8:709-21.

15. Russlies M, Behrens P, Ehlers EM, et al. Periosteum stimulates subchondral bone densification in autologous chondrocyte transplantation in a sheep model. Cell Tissue Res 2005;319:133-42.

16. Goodrich LR, Hidaka C, Robbins PD, Evans CH, Nixon AJ. Genetic modification of chondrocytes with insulin-like growth factor-1 enhances cartilage healing in an equine model. J Bone Joint Surg [Br] 2007;89-B:672-85

17. Saris DB, Dhert WJ, Verbout AJ. Joint homeostasis: the discrepancy between old and fresh defects in cartilage repair. J Bone Joint Surg [Br] 2003;85-B:1067-76.

18. Verbruggen $\mathbf{G}$, Wittoek $\mathbf{R}$, Groenboer $\mathbf{S}$, et al. Osteochondral repair in synovial joints. Curr Opin Rheumatol 2007;19:265-71.

19. Horas U, Pelinkovic D, Herr G, Aigner T, Schnettler R. Autologous chondrocyte implantation and osteochondral cylinder transplantation in cartilage repair of the knee joint: a prospective, comparative trial. J Bone Joint Surg [Am] 2003;85-A:185-92.

20. Knutsen G, Engebretsen L, Ludvigsen TC, et al. Autologous chondrocyte implantation compared with microfracture in the knee: a randomized trial. J Bone Joint Surg [Am] 2004;86-A:455-64

21. Krishman SP, Skinner JA, Carrington RW, et al. Collagen-covered autologous chondrocyte implantation for osteochondritis dissecans of the knee: two- to sevenyear results. J Bone Joint Surg [Br] 2006;88-B:203-5.

22. Ruano-Ravina A, Jato Diaz M. Autologous chondrocyte implantation: a systematic review. Osteoarthritis Cartilage 2006;14:47-51.

23. Wasiak J, Clar C, Villaneuva E. Autologous cartilage implantation for full thickness articular cartilage defects of the knee. Cochrane Database Syst Rev 2006;3:CD003323.
24. Strauss EJ, Goodrich LR, Chen CT, Hidaka C, Nixon AJ. Biochemical and biomechanical properties of lesion and adjacent articular cartilage after chondral defect repair in an equine model. Am J Sports Med 2005:33:1647-53.

25. No authors listed. ETS 123 - Multilateral consultation of parties to the european convention for the protection of vertebrate animals used for experimential and other scientific purposes CONS Strasburg, 1997

26. Green CJ, Knight J, Precious S, Simpkin S. Ketamine alone and combined with diazepam or xylaxine in laboratory animals: a 10 year experience. Lab Anim 1981;15:163-70.

27. Nowrouzian I, Schels HF, Ghodsian I, Karimi H. Evaluation of the anaesthetic properties of ketamine/xylazine/atropine combination in sheep. Vet Rec 1981;108:354-6.

28. Mama R, Wagner AE, Steffey EP, et al. Evaluation of xylazine and ketamine for total intravenous anesthesia in horses. Am J Vet Res 2005;66:3617-29.

29. Dorotka R, Windberger U, Macfelds $K$, et al. Repair of articular cartilage defects treated by microfracture and a three-dimensional collagen matrix. Biomaterials 2005;26:3617-29

30. Duda GN, Maldonado ZM, Klein P, et al. On the influence of mechanical conditions in osteochondral defect healing. J Biomech 2005;38:843-51.

31. Brittberg $\mathbf{M}$, Winalski CS. Evaluation of cartilage injuries and repair. J Bone Joint Surg [Am] 2003;85-A(Suppl 2):58-69

32. Romeis B. Mikroskopische Technik, 17th ed. Munich: Urban and Schwarzenberg, 1989.

33. Mainil-Varlet $\mathbf{P}$, Aigner T, Brittberg $\mathbf{M}$, et al. Histological assessment of cartilage repair: a report by the Histology Endpoint Committee of the International Cartilage Repair Society (ICRS). J Bone Joint Surg [Am] 2003;85-A(Suppl 2):45-57.

34. Rudert M. Histological evaluation of osteochondral defects: consideration of anima models with emphasis on the rabbit, experimental setup, follow-up and applied methods. Cells Tissues Organs 2002;171:229-40.

35. Mankin HJ, Dorfman H, Lippiello L, Zarins A. Biochemical and metabolic abnormalities in articular cartilage from osteo-arthritis human hips. II: correlation of morphology with biochemical and metabolic data. J Bone Joint Surg [Am] 1971;53-A:523-37.

36. Colwell CW Jr, D'Lima DD, Hoenecke HR, et al. In vivo changes after mechanica injury. Clin Orthop 2001;391 (Suppl):116-23.

37. van der Sluijs JA, Geesink RG, van der Linden AJ, et al. The reliability of the Mankin score for osteoarthritis. J Orthop Res 1992;10:58-61.

38. Bail H, Klein P, Kolbeck S, et al. Systemic application of growth hormone enhances the early healing phase of osteochondral defects: a preliminary study in micropigs. Bone 2003;32:457-67.

39. Jackson DW, Lalor PA, Aberman HM, Simon TM. Spontaneous repair of fullthickness defects of articular cartilage in a goat model: a preliminary study. J Bone Joint Surg [Am] 2001;83-A:53-64.

40. Aroen A, Loken S, Heir S, et al. Articular cartilage lesions in 993 consecutive knee arthroscopies. Am J Sports Med 2004;32:211-15.

41. Convery FR, Akeson WH, Keown GH. The repair of large osteochondral defects: an experimental study in horses. Clin Orthop 1972;82:253-62.

42. Hurtig MB, Fretz PB, Doige CE, Schnurr DL. Effects of lesion size and location on equine articular cartilage repair. Can J Vet Surg 1988;52:137-46.

43. Vasara Al, Hyttinen MM, Lammi MJ, et al. Subchondral bone reaction associated with chondral defect and attempted cartilage repair in goats. Calcif Tissue Int 2004;74:107-14.

44. Spahn G, Plettenberg H, Nagel H, et al. Evaluation of cartilage defects with nearinfrared spectroscopu (NIR): an ex vivo study. Med Eng Phys 2008;30:285-92.

45. Guettler JH, Demetropoulos CK, Yang KH, Jurist KA. Osteochondral defects in the human knee: influence of defect size on cartilage rim stress and load redistribution to surrounding cartilage. Am J Sports Med 2004;32:1451-8.

46. Burr DB, Schaffler MB. The involvement of subchondral mineralized tissues in osteoarthrosis: quantitative microscopic evidence. Microsc Res Tech 1997;37:343-57.

47. Yang JP, Bogoch ER, Woodside TD, Hearn TC. Stiffness of trabecular bone of the tibia plateau in patients with rheumatoid arthritis of the knee. J Arthroplasty 1997; 12:798-803

48. Buckwalter JA, Mankin HJ. Articular cartilage. Part II: degeneration and osteoarthrosis, repair, regeneration, and transplantation. J Bone Joint Surg [Am] 1997;79A:612-32.

49. Goldring MB, Goldring SR. Osteoarthritis. J Cell Physio/ 2007;213:626-34.

50. Mastbergen SC, Marijnissen AC, Vianen ME, et al. The canine 'groove' model of osteoarthritis is more than simply the expression of surgically applied damage. Osteoarthritis Cartilage 2006;14:39-46.

51. Wei L, Svensson 0, Hjerpe A. Correlation of morphologic and biochemical changes in the natural history of spontaneous osteoarthrosis in guinea pigs. Arthritis Rheum 997:40:2075-83.

52. Kleemann RU, Krocker D, Cedraro A, Tuischer J, Duda GN. Altered cartilage mechanics and histology in knee osteoarthritis: relation to clinical assessment (ICRS Grade). Osteoarthritis Cartilage 2005;13:958-63. 
53. Matsui H,. Shimizu M, Tsuji H. Cartilage and subchondral bone interaction in osteoarthrosis of human knee joint: a histological and histomorphometric study. Microsc Res Tech 1997:37:333-42.

54. O'Driscoll SW. The healing and regeneration of articular cartilage. J Bone Joint Surg [Am] 1998;80-A:1795-812.
55. Rand JS, Ilstrup DM. Survivorship analysis of total knee arthroplasty: cumulative rates of survival of 9200 total knee arthroplasties. J Bone Joint Surg [Am] 1991;73A:397-409.

56. Biant LC, Bentley G. Stem cells and debrided waste: two alternative sources of cells for transplantation of cartilage. J Bone Joint Surg [Br] 2007;89-B:1110-14 